\title{
Treatment of Renal Colic by Nerve Blockade with Lidocaine Versus Intravenous Dexketoprofen
}

\author{
Avni Uygar Seyhan and Erdal Yılmaz \\ Department of Emergency Medicine, Kartal Dr. Lütfi Kırdar City Hospital, Istanbul, Turkey
}

\begin{abstract}
Objective: To compare non-steroidal anti-inflammatory drugs (NSAIDs) with spinal nerve blockade of related dermatomes using lidocaine for pain palliation of patients admitted to the Emergency Department (ED) with an episode of renal colic.

Study Design: Randomised controlled-trial.

Place and Duration of study: Department of Emergency Medicine, Kartal Dr. Lütfi Kırdar City Hospital, i̇stanbul, Turkey from May to July 2019.

Methodology: The study included patients admitted to the ED with renal colic randomised into two groups: first group received $2 \%$ lidocaine for nerve blockage and the second group received intravenous injection of $50 \mathrm{mg}$ dexketoprofen. All patients were asked to rate the intensity of their pain and on a 0 to 10 point visual analogue scale before and at $5,15,30,45$, and 60 minutes after intervention.

Results: A total of 126 patients, 56 women and 70 men, were inducted. There were statistically significant differences in the median VAS scores for pain from the 5th minute to the 60th minute in favour of lidocaine.

Conclusion: Spinal nerve blocks with $2 \%$ lidocaine resulted in greater short-term pain relief than intravenous dexketoprofen in ED patients with renal colic.
\end{abstract}

Key Words: Renal colic, NSAID, lidocaine, Nerve blockade.

How to cite this article: Seyhan AU, Yılmaz E. Treatment of Renal Colic by Nerve Blockade with Lidocaine Versus Intravenous Dexketoprofen. J Coll Physicians Surg Pak 2021; 31(08):921-925.

\section{INTRODUCTION}

Typically, reno-ureteral colic is caused by obstruction of the renal pelvis or ureter with a stone; and the spasm which occurs in the pelvis, renal capsule and ureter, causes stretching of these structures and subsequently causes severe pain. ${ }^{1,2}$ This pain is sudden in onset, intense, and localised at the costovertebral angle below the twelfth rib. The site of pain is variable and depends on the place of occlusion. Pain may be felt in the inguinal region, testicles or labia majora. If the stone is located at the ureterovesical junction, symptoms such as dysuria, excessive urination, and vesical tenesmus can typically be seen. Nausea and vomiting are the commonest related gastrointestinal symptoms. ${ }^{3}$

Most patients report that renal colic pain is the most severe pain they have ever experienced, and it is often difficult to be controlled. ${ }^{4,5}$

Correspondence to: Dr. Erdal Yllmaz, Department of

Emergency Medicine, Kartal Dr. Lütfi Kirdar City

Hospital, Istanbul, Turkey

E-mail: erdalyilmazmd@gmail.com

Received: December 25, 2020; Revised: June 03, 2021;

Accepted: July 16, 2021

DOI: https://doi.org/10.29271/jcpsp.2021.08.921
Although paracetamol, NSAIDs, and opioid drugs such as morphine are among the medical treatment options, sometimes surgical treatment may be required. ${ }^{6,7}$ While the analgesic effectiveness of the medications used is known, a quicker effect is often needed in clinical practice due to the intensity of the pain ${ }^{8}$.

The aim of this study was to compare NSAIDs with spinal nerve blockade of related dermatomes using lidocaine for pain palliation of patients admitted to the ED with an episode of renal colic.

\section{METHODOLOGY}

The study was designed as a prospective, observational, randomised controlled trial (RCT), conducted at the Department of Emergency Medicine, Kartal Dr. Lütfi Kırdar City Hospital, İstanbul, Turkey from May to July 2019. The study gained approval from the local Ethics Committee; (Ethics Committee Ruling No. 2019/514/154/21). Informed consents of all participating patients were ensured through signature on a form. All authors had full access to all study data.

This research included patients, who presented with renal colic complaints to the ED between $1^{\text {st }}$ May 2019 and $31^{\text {st }}$ July 2019. All patients admitted to the ED for acute renal colic, who were subsequently diagnosed with ureteral or kidney stones by non-contrast enhanced computed tomography (CT), were included in the 
study groups. Patients under the age of 18 and over 70 years of age, patients with ureteral stent, patients with skin rash or lesions in the region to be injected, patients who used drugs that disrupt the coagulation cascade, patients with allergy to lidocaine or dexketoprofen, and patients who used analgesic medication four hours before their presentation to the Emergency Department were excluded from this study.

In this study, the authors aimed to compare NSAIDs with spinal nerve blockage of related dermatomes using lidocaine. Eligible participants were assigned randomly to one of the two treatment groups through the means of a computer-generated lottery system.

In first group, before applying the treatment, the skin of the patients was disinfected using an appropriate antiseptic solution. Intradermal injection of a local anesthetic agent ( $2 \%$ lidocaine, $2.5 \mathrm{cc}$ from a $100 \mathrm{mg}-5 \mathrm{cc}$ ampoule mixed with $2.5 \mathrm{cc}$ normal saline) was applied to the spinal segments T10-11-12 and L1-2, which represented the renal and ureteral spinal segments, and over the spinous processes and $1 \mathrm{~cm}$ lateral to the middle of the two spinous processes that were suitable for the dermatome area. Patients in the second group were given $50 \mathrm{mg}$ dexketoprofen intravenously (IV) in $100 \mathrm{cc}$ isotonic solution.

In order to assess patients' relative pain levels, the visual analogue scale (VAS) was utilised in order to design a form. ${ }^{9}$ Patients' scores were depicted on linear scales $100 \mathrm{~mm}$ in length. Patients noted their pain levels as a mark on the linear scales where $0 \mathrm{~mm}$ indicated "no pain" with $100 \mathrm{~mm}$ corresponding to "most severe pain you've ever felt". Patients were evaluated six times: prior to the administration of the assigned treatment and at $5,15,30,45$, and 60 minutes. To assess patients' respective pain outcomes, measurements were carried out in millimetres, using a ruler.

Administration of $100 \mathrm{mg}$ of gluteal intramuscular tramadol was applied as necessary as rescue therapy. The number of patients, identified as requiring rescue therapy, was noted in each group. VAS was used as the assessment scale in the study. VAS values were obtained at the 5 th, 15th, 30th, 45th and 60th minute after the treatments were applied; and these data were used in the analysis.

The power analysis was used to estimate the minimum sample size required in this research. This analysis suggests that the study would have to include at least minimum 124 patients with 0.05 significance level and $90 \%$ power of thetest.

Statistical analyses were carried out through the IBM SPSS Version 23 statistical analysis programme. Data are summarised by calculating means, standard deviations, medians, the first and third quantiles, percentages and totals. Kolmogorov-Smirnov and Shapiro-Wilktests were used to test whether the data was distributed normally. Since data were not normally distributed, non-parametric tests were conducted to contrast the mean ranks of groups. Therefore, Friedman tests were utilised to identify differences among dependent groups, and Mann-Whitney U-Test for two independent groups. The alpha threshold of all tests was set as 0.05 to compare p values.

\section{RESULTS}

This research was conducted with 148 patients. Some of patients were excluded as they refused to participate in the study, and others did not meet the requirements for inclusion criteria (Figure 1). In 63 patients, the use of $2 \%$ lidocaine hydrochloride intradermally to the corresponding renal and urethral dermatome regions (spinal segments T10, T11, T12, $L 1, L 2$ ) provided pain palliation. In the other 63 patients, pain palliation was achieved by intravenous administration of $50 \mathrm{mg}$ dexketoprofen.

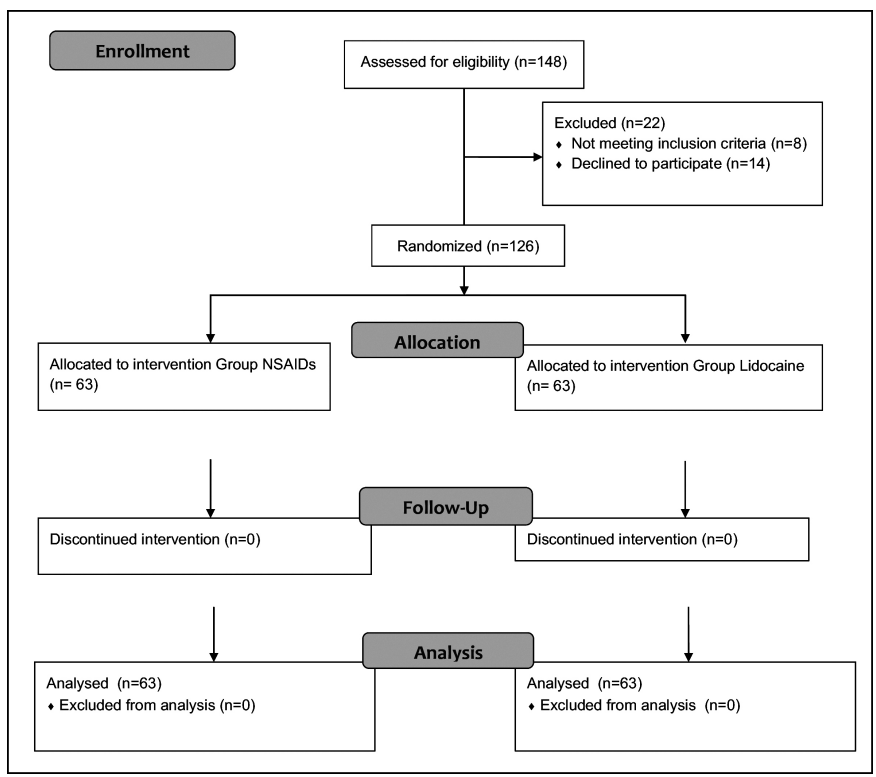

Figure 1: CONSORT diagram of patients' randomisation, intervention, and analysis.

Table I: Gender and age distribution of patients belonging to the groups in which the medications were administered.

\begin{tabular}{|l|c|c|c|}
\hline & \multicolumn{2}{|c|}{ Gender } & \multirow{2}{*}{ Total } \\
\hline Medication type & Female & Male & \\
\hline Dexketoprofen & $29(46.03 \%)$ & $34(53.97 \%)$ & 63 \\
\hline Lidocaine hydrochloride & $27(42.86 \%)$ & $36(57.14 \%)$ & 63 \\
\hline Total & $56(44.44 \%)$ & $70(55.56 \%)$ & 126 \\
\hline & \multicolumn{2}{|c|}{ Age } & \\
\hline Medication type & Mean & $\mathrm{N}$ & Standard deviation \\
\hline Dexketoprofen & 36.44 & 63 & 11.66 \\
\hline Lidocaine hydrochloride & 35.48 & 63 & 10.84 \\
\hline Total & 35.96 & 126 & 11.22 \\
\hline
\end{tabular}

Of the patients included in the study, $44.44 \%$ were females ( $n=$ $56)$, and $55.56 \%$ were males $(n=70)$. The gender distribution of the groups to which the drugs were administered is given in Table I. The patient ages, included in the analysis, range from 19 to 61 years. The mean age was determined as $35.96 \pm 11.22$ years. The mean ages of the groups to which the drugs were administered are shown in Table I. The medians of the pain intensity of the patients before ( $0 \mathrm{~min})$ and at the $5^{\text {th }}, 15^{\text {th }}, 30^{\text {th }}$, $45^{\text {th }}$ and $60^{\text {th }}$ minute before taking the relevant drugs are shown inTable II. 
Table II: Median and quantiles of pain intensity.

\begin{tabular}{|c|c|c|c|c|c|c|c|c|}
\hline \multirow{2}{*}{\multicolumn{2}{|c|}{ Medication Type }} & \multicolumn{6}{|c|}{ Pain intensity } & \multirow{3}{*}{$\begin{array}{c}\begin{array}{c}\text { p-values of } \\
\text { fried-man } \\
\text { tests }\end{array} \\
<0.001\end{array}$} \\
\hline & & \multirow{2}{*}{$\begin{array}{c}\begin{array}{c}\mathbf{0} \\
\mathbf{m i n}\end{array} \\
9(7-10)\end{array}$} & \multirow{2}{*}{$\begin{array}{c}\begin{array}{c}5 \\
\text { min }\end{array} \\
7(5-9)\end{array}$} & \multirow{2}{*}{$\begin{array}{c}\begin{array}{c}15 \\
\mathbf{m i n}\end{array} \\
5(3-8)\end{array}$} & \multirow{2}{*}{$\begin{array}{c}\begin{array}{c}30 \\
\text { min }\end{array} \\
3(1-5)\end{array}$} & \multirow{2}{*}{\begin{tabular}{c|c|}
$\begin{array}{c}45 \\
\mathrm{~min}\end{array}$ \\
$2(1-6)$ \\
\end{tabular}} & \multirow{2}{*}{$\begin{array}{c}\begin{array}{c}60 \\
\text { min }\end{array} \\
1(1-6)\end{array}$} & \\
\hline $\begin{array}{l}\text { Dexketoprofen } \\
(\mathrm{N}=63)\end{array}$ & Median (Q1-Q3) & & & & & & & \\
\hline $\begin{array}{l}\text { Lidocaine hydrochloride } \\
(\mathrm{N}=63)\end{array}$ & Median (Q1-Q3) & $9(7-10)$ & $5(3-8)$ & $4(2-6)$ & $2(0-3)$ & $1(0-2)$ & $0(0-1)$ & $<0.001$ \\
\hline $\begin{array}{l}\text { Mann Whitney Test } \\
\text { Results }\end{array}$ & p-values & - & 0.041 & 0.024 & 0.003 & $<0.001$ & $<0.001$ & \\
\hline
\end{tabular}

It was observed that dexketoprofen and lidocaine hydrochloride medications significantly decreased the pain severity of the patients during the $5^{\text {th }}, 15^{\text {th }}, 30^{\text {th }}, 45^{\text {th }}$ and $60^{\text {th }}$ minute according to the median and show that by passing time for both medications, they provide statistically significant decrease in the pain intensity (both $p$-values $<0.001$ ).

The results show that lidocaine hydrochloride relieves pain more than dexketoprofen. Similar results were obtained at 5 , $15,30,45$ and $60^{\text {th }}$ minute (Table II, all p-values $<0.05$ ). Lidocaine hydrochloride in all minutes tested is shown to be more effective in relieving the pain intensity. Finally, none of the patients in the two groups had side effects due to the drugs, and no patients received salvage therapy.

\section{DISCUSSION}

The aim of this study was to compare NSAIDs with spinal nerve blockade of related dermatome using lidocaine for pain palliation of patients admitted to the ED with an episode of renal colic. VAS scores of the patients were evaluated at the time of presentation and at $5^{\text {th }}, 15^{\text {th }}, 30^{\text {th }}, 45^{\text {th }}$, and 60th minute after treatment. In this study, the authors concluded that although both drugs caused a significant decrease in VAS scores after the $5^{\text {th }}$ minute, the pain severity of the patients who took lidocaine compared to the patients who took dexketoprofen; at all time intervals checked were significantly less.

Renal colic is a medical emergency that needs to be diagnosed and treated quickly. It is estimated that at any stage in life, the risk of developing renal colic varies from $1 \%$ to $10 \%$, and the rate of recurrence can be as high as $50 \%$. The treatment aims at relieving pain and maintaining kidney function by ureteral relief of obstruction, and the medications to be used in the treatment are expected to be medications with limited side effects and rapid response..$^{10,11}$

The analgesic effect of NSAIDs is attributed to the blocking of prostaglandin synthesis. It also reduces edema, inflammation, and ureteral muscle activity. NSAIDs effectively reduce pain, but potentially decrease the flow of renal blood, interfering with the renal autoregulation in response to obstruction. ${ }^{12}$ This condition is well tolerated in healthy individuals, but kidney failure may be induced in patients with pre-existing kidney disease. Cardiac patients are also at risk of developing heart failure and cardiac decompensation. ${ }^{13}$

Lidocaine is a widely administered drug for palliation of various types of pain. By reducing afferent sensory transmission, lidocaine alters the tone of sympathetic smooth muscle, resulting in substantial pain reduction. ${ }^{14}$ Lidocaine's analgesic properties continue for a longer duration despite a decrease in plasma levels. In other words, lidocaine suppresses the potential evoked even at low doses; and provides strong analgesic outcomes. ${ }^{15,16}$

There are many studies in the literature investigating the effectiveness of lidocaine in the management of renal colic. Contrasting the pain-relieving effects of intravenous (IV) morphine with IV lidocaine in patients admitted to the Emergency Department with renal colic, Soleimanpour et al. reported a substantial reduction in pain scale in patients receiving lidocaine as opposed to the morphine group. ${ }^{14}$ The study conducted by Iguchi et al. investigated the outcomes of local lidocaine injection at the trigger points of renal colic patients and showed that this intervention provided vastly improved outcomes over the combination of IV butylskopolamine and sulpyrine in the treatment of renal colic pain. ${ }^{17}$ In a study, conducted by Firouzian et al., patients presented to the Emergency Department with renal colic, the effectiveness of lidocaine treatments combined with morphine and morphine alone was compared, and it was reported that the use of lidocaine in combination with morphine was more effective in reducing pain and side effects. ${ }^{18}$ In a study conducted by Maldonado-Avila et al., they performed a twelfth intercostal nerve block with lidocaine and compared this treatment with intramuscular ketorolac, and reported that lidocaine was more effective and faster in relieving pain. ${ }^{19}$

In this study, after starting treatment the average VAS score of the patients who underwent spinal nerve blockade of related dermatome with lidocaine was lower than that of the patients who were given dexketoprofen IV; and thus, the authors may claim that lidocaine was more effective in pain relief.

This study had some limitations. By identifying a small number of patients in a single academic institution, this study potentially limits the generalisation of results with other populations. The research does not involve assessing 
the recurrence of pain (beyond 60 mins) and the related side effects of the medications. Another drawback is that the pain assessment is dependent upon the patients' subjective reaction.

\section{CONCLUSION}

Spinal nerve blocks with $2 \%$ lidocaine resulted in greater short-term pain relief than intravenous dexketoprofen in ED patients with renal colic. Better designed randomised clinical trials, intended to check the safety and effectiveness of lidocaine in the treatment of renal colic pain, should be performed.

\section{ETHICAL APPROVAL:}

This study was conducted with the approval from the Ethics Committee of the Kartal Dr. Lütfi Kırdar City Hospital, Istanbul, Turkey.

\section{PATIENTS' CONSENT:}

All patients signed a document of informed consent.

\section{CONFLICT OF INTEREST:}

The authors declared no conflict of interest.

\section{AUTHORS' CONTRIBUTION:}

AUS: Interpretation of data for the work; drafting the work; and revising it critically for important intellectual content.

EY: Revising it critically for important intellectual content; and final approval of the version to be published.

\section{REFERENCES}

1. Pedersen KV, Drewes AM, Frimodt-Moller PC, Osther PJ. Visceral pain originating from the upper urinary tract. Urol Res 2010; 38(5):345-55. doi: 10.1007/s00240010-0278-1.

2. Rohat AK, Kurt E, Şenel Ç. The comparison of two prediction models for ureteral stones: CHOKAI and STONE scores. Am J Emerg Med 2021; 44:187-191. doi: 10.1016/ j.ajem.2020.08.099.

3. Bultitude M, Rees J. Management of renal colic. BMJ 2012; 345:e5499. doi: http://doi.org/10.1136/bmj.e5499.

4. Esquena S, Millan Rodriguez F, Sanchez-Martin FM, Rousaud Baron F, Marchant F, Villavicencio Mavrich $\mathrm{H}$. Renal colic: revision of literature and scientic evidence. Actas Urol Esp 2006; 30(3):268-80. doi: 10.1016/s02104806(06)73439-8

5. Leveridge M, D'Arcy FT, O'Kane D, Ischia JJ, Webb DR, Bolton DM, et al. Renal colic: Current protocols for emergency presentations. Eur J Emerg Med 2016; 23(1): 2-7. doi: 10.1097/MEJ.0000000000000374.

6. Knoedler JJ, Lieske JC. Non-steroidal anti-in ammatory drugs for renal colic. Lancet 2016; 387(10032):1971-2. doi: http://doi.org/10.1016/S0140-6736(16)00745-5.

7. Türk C, Petř́k A, Sarica K, Seitz C, Skolarikos A, Straub M, Knoll T. "EAU guidelines on diagnosis and conservative management of urolithiasis." Eur Urol 2016; 69(3):
468-74. doi: 10.1016/j.eururo.2015.07.040.

8. Moussa M, Papatsoris AG, Abou Chakra M. Intradermal sterile water injection versus diclofenac sodium in acute renal colic pain: A randomized controlled trial. Am J Emerg Med 2021; 44:395-400. doi: 10.1016/j.ajem. 2020.04.079.

9. Hokenek NM, Erdogan MO, Hokenek UD, Algin A, Tekyol D, Seyhan AU. Treatment of migraine attacks by transcutaneous electrical nerve stimulation in emergency department: A randomize controlled trial. Am J Emerg Med 2021; 39: 80-5. doi:10.1016/j.ajem.2020.01.024.

10. Pathan SA, Mitra B, Straney LD, Afzal MS, Anjum S, Shukla $D$, et al. Delivering safe and effective analgesia for management of renal colic in the emergency department: A double-blind, multigroup, randomised controlled trial. Lancet 2016; 387(10032):1999-2007. doi: http:// doi.org/10.1016/S0140-6736(16)00652-8.

11. KandaSwamy GV, Dhanasekaran AK, Elangovan A, John B, Viswaroop B, Vedanayagam KS. Randomized double blinded placebo controlled trial comparing diclofenac and pirox- icam in management of acute renal colic and its clinical implications. Urol J 2015; 12(2):2069-73. doi: http://doi.org/10.22037/uj.v12i2.2878.

12. Perlmutter A, Miller L, Trimble LA, Marion DN, Vaughan Jr ED, Felsen D. Toradol, an NSAID used for renal colic, decreases renal perfusion and ureteral pressure in a canine model of unilateral ureteral obstruction. J Urol 1993; 149(4): 926-30. doi: http://doi.org/10.1016/ S0022-5347(17)36261-4.

13. Bleumink GS, Feenstra J, Sturkenboom MC, Stricker BH. Nonsteroidal anti-inflammatory drugs and heart failure. Drugs 2003; 63(6):525-34. doi: 10.2165/00003495200363060-00001.

14. Soleimanpour H, Hassanzadeh K, Vaezi H, Golzari SE, Esfanjani RM. Soleimanpour M. Effectiveness of intra-venous lidocaine versus intravenous morphine for patients with renal colic in the emergency department. $B M C$ Urol 2012; 12(1): 1-5. doi:10.1186/ 1471-2490-12-13.

15. Couceiro TCDM, Lima LC, Couceiro LM, Valença MM. Intravenous lidocaine to treat postoperative pain. RevistaDor 2014; 15(1):55-60. doi: 10.5935/ 1806-0013.20140013.

16. Abelson KS, Höglund AU. Intravenously administered lidocaine in therapeutic doses increases the intraspinal release of acetylcholine in rats. Neurosci Lett 2002; 317(2): 93-6. doi: http://doi.org/10.1016/ S0304-3940(01)02440-5.

17. Iguchi M, Katoh $Y$, Koike H, Hayashi T, Nakamura M. Randomized trial of trigger point injection for renal colic. Int J Urol 2002; 9(9):475-9. doi: 10.1046/ j.1442-2042.2002.00504.x.

18. Firouzian A, Alipour A, Dezfouli HR, Kiasari AZ, Baradari $A G$, Zeydi, A, et al. Does lidocaine as an adjuvant to morphine improve pain relief in patients presenting to the ED with acute renal colic? A double-blind, randomized controlled trial. Am J Emerg Med 2016; 34(3):443-8. doi: 10.1016/j.ajem.2015.11.062.

19. Maldonado-Avila M, Del Rosario-Santiago M, Rosas-Nava JE, Manzanilla-Garcia HA, Rios-Davila VM, Rodriguez-Nava 
$P$, et al. Treatment of reno-ureteral colic by twelfth intercostal nerve block with lidocaine versus intramuscular diclofenac. Int Urol Nephrol 2017; 49(3): 413-7. doi:10.1007/s11255-016-1479-5.

$\bullet \bullet \bullet \bullet \bullet \bullet \bullet \bullet \bullet$ 